\title{
Lifelong learning as a clinical academic key to job satisfaction
}

\author{
Steffen E Petersen ${ }^{1,2}$, MSC MPH MD DPhil SFHEA FRCP FSCMR FACC FEACVI FESC
}

1. William Harvey Research Institute, NIHR Barts Biomedical Research Centre, Queen Mary University of London, Charterhouse Square, London, EC1M 6BQ, UK.

2. Barts Heart Centre, St Bartholomew's Hospital, Barts Health NHS Trust, West Smithfield, EC1A 7BE, UK

When I started to study medicine, I had a narrow view of what a doctor's job looks like. Looking back over the last 20 years since my graduation, I now appreciate that medicine provides some of the most exciting opportunities and can lead to diverse roles. I hope by providing you with a personal glimpse into my career that you may reflect on your own plans and development.

I am driven not only by personal ambition but mostly, I think, by wanting to make a positive impact on patients, the public, colleagues and trainees. I enjoy lifelong learning, but a clinical academic career has challenges. Given we all have limited time to spare, there is a tension between clinical and academic excellence. There is also tension when striving for academic excellence - should one become the world expert in a narrow research topic or have multiple research interests. We can only try and find the right balance. Also, as a clinical academic, there is more uncertainty about job security than in a clinical job. I love learning, and I personally prefer structured learning. This is why I have many degrees.

My first clinical job after graduating in Germany involved cardiac magnetic resonance (CMR) research. I was lucky to be amongst the pioneers of the technique and to witness major breakthroughs in CMR image acquisition and analysis. My research was very focused on methodological research in the early days. Nearing the end of my cardiology training, I feel privileged to have been involved in advising UK Biobank on enhancing this phenomenal research platform with cardiac imaging in 100,000 of the original 500,000 participants[1]. Through this work, I became increasingly aware of the potential of big data population research and the huge opportunities it could provide for cardiovascular research. I met many worldleading epidemiologists, which inspired me to sign up for a part-time Masters in Public Health at Harvard School of Public Health. I hoped that this would equip me with the skillset to contribute impactful work using the UK Biobank.

I started the "Program for Clinical Effectiveness" at the Harvard School of Public Health during one summer and quickly realised I wanted to complete the entire Masters of Public Health programme over three summers[2]. The course modules allowed me to pick mostly quantitative subjects I wanted to learn about - e.g. various statistics modules including linear, logistic and 
Cox regression as well as basic and specialised (e.g. environmental, social) epidemiology. This programme gave me the confidence to lead a research programme that now applies these tools in the large CMR imaging programme in UK Biobank. I also met wonderful international friends and colleagues, who are now valued collaborators.

I had my first exposure to Decision Analysis during the MPH at Harvard School of Public Health, which I enjoyed immensely. It was an honour to learn the basics from Dr Milt Weinstein, one of the first to describe Quality-Adjusted Life Years (QALY)[3]. In the advanced course, Dr Myriam Hunink encouraged us all to develop economic models of interest to us, and I am pleased that beyond the degree I managed to publish this work on the cost-effectiveness of the polypill in primary prevention with the wonderful support from Dr Hunink and her then teaching assistant, Dr Bart Ferket[4]. I could now see the value of application of such economic evaluations to my primary area of expertise - cardiac imaging[5]. However, I felt I need to learn more about the "cost" components of cost-effectiveness studies. When I heard about the Executive MSc Health Economics, Outcomes and Management in Cardiovascular Science at the London School of Economics, I immediately wanted to join[6].

I feel that this Executive MSc at the London School of Economics broadened my horizon and helped me frame my research to be more impactful. The course content covered a broad range of topics, training us to use research tools such as quasi-experimental study designs, systematic reviews and meta-analyses, and quality improvement projects. I enjoyed the modules on economic analysis, economic evaluation, financing in healthcare and principles of health technology assessments. These classes always provided theoretical frameworks but benefitted from the international students in the class. Students, through the sharing of experience and knowledge, ensured we would have a broad appreciation of how important the context is in health economics. The experience from this degree led to a number of projects related to advocacy for cardiovascular imaging. Participating in this course opened doors: I was invited to join the European Society of Cardiology's (ESC) Clinical Practice Guidelines committee which has a major impact on Cardiology practice globally. Since my degree, I have contributed to the ESC Atlas of Cardiology Project. This project highlights that despite huge advances in clinical sciences, cardiovascular disease remains the world's biggest killer. With data from over 50 countries this project underlines major healthcare gaps and inequalities[7].

My work has taken me to places that I could not possibly have envisaged all those years ago when I started to study Medicine. My eagerness to learn, develop, and recognise new opportunities have been key to my successes. I am passionate about mentoring and nurturing trainees and enjoy supporting them to unleash their potential. This part of my job brings huge job satisfaction. I know I want to continue to learn until and beyond my retirement. I hope trainees and colleagues will, at times, pause to reflect on what motivates them in their careers. For me, the key is to enjoy what you are doing most of the time now, but also to take a forward-thinking approach and consider what you may wish to do to ensure you still enjoy your job most of the time in five or ten years' time. This is where lifelong learning is key to me. I often feel I am Jack 
of all trades, master of none. And even if this was true, I have had a wonderful 28 years since starting to study medicine, and I expect to still enjoy my career for the next 15-20 years until my retirement.

References

$1 \quad$ UK Biobank. www.ukbiobank.ac.uk (accessed 29 Sep2020).

2 Harvard School of Public Heath; Summer Program in Clinical Effectiveness. https://www.hsph.harvard.edu/clinical-effectiveness/ (accessed 29 Sep2020).

3 Weinstein MC, Stason WB. Foundations of Cost-Effectiveness Analysis for Health and Medical Practices. N Engl J Med 1977;296:716-21. doi:10.1056/NEJM197703312961304

4 Ferket BS, Hunink MGM, Khanji M, et al. Cost-effectiveness of the polypill versus risk assessment for prevention of cardiovascular disease. Heart 2017;103:483-91. doi:10.1136/heartjnl-2016-310529

5 Genders TSS, Petersen SE, Pugliese F, et al. The Optimal Imaging Strategy for Patients With Stable Chest Pain. Ann Intern Med 2015;162:474. doi:10.7326/M14-0027

6 The London School of Economics and Political Science; Executive MSc Health Exonomics, Outcomes and Management in Cardiovascular Sciences. https://www.lse.ac.uk/study-at-lse/Graduate/Degree-programmes-2020/Executive-MScHealth-Economics-Outcomes-Management-Cardiovascular-Sciences (accessed 29 Sep2020).

7 Timmis A, Townsend N, Gale CP, et al. European Society of Cardiology: Cardiovascular Disease Statistics 2019. Eur Heart J 2020;41:12-85. doi:10.1093/eurheartj/ehz859 